\title{
REFERENCES
}

Archibald, R. M. (1944). J. biol. Chem. 154, 643.

Coulson, R. A., Ellinger, P. \& Holden, M. (1944). Biochem. $J .38,150$.

Ellinger, P. (1946a). Biochem. J. 40, xxxi.

Ellinger, P. (1946b). Biochem. J. 40, xxxiii.

Ellinger, P. \& Coulson, R. A. (1944). Biochem. J. 38, 265.

Ellinger, P., Fraenkel, G. \& Abdel Kader, M. M. (1947). Biochem. J. 41, 559.

Johnson, B. C. (1945). J. biol. Chem. 159, 227.

König, W. (1904).' J. prakt. Chem. 69, 105.
Koser, S. A., Berkman, S. \& Dorfman, A. (1941). Proc: Soc. exp. Biol., N.Y., 47, 504.

Krebs, H. A. (1933). Hoppe-Seyl. Z. 217, 191.

Krebs, H. A. (1935). Biochem. J. 29, 1951.

Krebs, H. A. \& Henseleit, K. (1932). Hoppe-Seyl.Z. 210,83.

Krehl, W. A., de la Huerga, J., Elvehjem, C. A. \& Hant, E. B. (1946). J. biol. Chem. 166, 53.

Perlzweig, W. A., Bernheim, M. L. C. \& Bernheim, F. (1943). J. biol. Chem. 150, 401.

Sarett, H. P. (1943). J. biol. Chem. 150, 159.

Scudi, J. K. (1946). Science, 108, 567.

\section{Electrophoretic Studies on Human Serum}

\author{
By H. HOCH, The Hale Clinical Laboratory, The London Hospital, E. 1
}

\section{(Received 9 June 1947)}

The purpose of the present work was to collect information of the extent to which the interpretation of electrophoretic patterns of serum proteins in phosphate buffer can account for 'boundary anomalies', an expression used by Tiselius (1930) and others to refer to small changes in field intensity and mobility across a boundary.

Although the nature of the changes in conductivity and ionic mobility across a protein boundary has been recognized for some time (Tiselius, 1930; Longsworth \& MacInnes, 1940 $a$; Abramson, Moyer \& Gorin, 1942), it is only recently that these changes have been given a detailed theoretical consideration (Svensson, 1943; Dole, 1945; Svensson, 1946). A theoretical treatment is here given which incorporates Svensson's conclusions on boundary anomalies and has been used to study in particular $(a)$ the relative migration velocities of the $\alpha_{2}$ and $A$ boundaries in human serum, and $(b)$ the conditions during electrophoresis of solutions containing protein components of nearly the same mobilities.

\section{Notation}

\section{THEORETICAL}

The symbols used are defined as follows:

$V_{i}=$ migration of protein $i$ (numbered from the fastest component) at infinite dilution in the buffer of concentration equal to that immediately below the $\epsilon$ boundary;

$V_{a i}=$ actual migration velocity of protein $i$ below its boundary in descending limb;

$r=$ ratio of velocities of the protein ions at infinite dilution in the bulk buffer to that in buffer below $\epsilon$ boundary;
$C_{i}=$ apparent concentration of protein $i$ on descending side $=\frac{\text { area under peak } i}{\text { total area desc. }-\epsilon} \times$ concentration of protein in starting solution;

$C_{1}{ }^{\prime}=$ apparent concentration of protein $i$ on ascending side $=\frac{\text { area under peak } i}{\text { total area asc. }-\delta} \times p \times$ concentration of protein in starting solution;

$C_{i}$ and $C_{1}{ }^{\prime}$ are expressed in $\mathrm{g} . / 100 \mathrm{ml}$;

$p=\frac{\text { mean of asc. and desc. total areas }-\delta}{\text { mean of asc. and desc. total areas }-\epsilon}$;

$a_{i}, a_{i}{ }^{\prime}=$ boundary displacements on the descending and ascending sides during an arbitrary time;

$K_{i}=$ coefficients as defined in the text;

$\kappa=$ conductivity;

$I=$ current per unit area of cross-section.

\section{Notation for Svensson's (1946) equation (23)}

$c_{i 1}=$ ionic concentrations in electrochemical equiv./ml. above colloid boundary, with the signs of the charges;

$u_{i 1}=$ ionic mobilities in cm. ${ }^{2} \mathrm{~V}^{-1}$ sec. $^{-1}$ above colloid boundary, with the signs of the charges;

$u_{2} / u_{1}=$ mobility ratio across the colloid boundary;

$C=$ concentration of a leading ion in equiv. $/ \mathrm{ml}$. with the sign of the charge;

$\mathbf{U}=$ mobility of colloid ion above the boundary, defined by equation (22) of Svensson (1946); $U=\bar{U}$ of Svensson;

$\kappa_{2} / \kappa_{1}=$ ratio of conductivities of solutions above and below the colloid boundary.

The displacement of the centroidal ordinate of the gradient curve of a boundary gives the migration velocity of the protein ion in the environment below its boundary (Longsworth, 1943). If the relative change in migration velocity of a protein ion, brought about by a change in the 
concentration of protein from zero to $C_{i}$ is put proportional to the protein concentration, i.e. $\left(V_{a i}-V_{i}\right) / V_{i}=K_{i} C_{i}$, then the velocity of, for example, the second slowest descending boundary is given by $V_{i-1}\left(1+K_{i} C_{i}+K_{i-1} C_{i-1}\right)$, that of the fastest ascending boundary by $r V_{1}\left(1+K_{1} C^{\prime}{ }_{1}\right)$. Generally:

$V_{1}\left(1+K_{i} C_{i}+K_{i-1} C_{i-1}+\ldots+K_{3} C_{3}+K_{2} C_{2}+K_{1} C_{1}\right):$

$V_{2}\left(1+K_{i} C_{i}+K_{i-1} C_{i-1}+\ldots+K_{3} C_{3}+K_{2} C_{2}\right): \ldots$ :

$V_{i}\left(1+K_{i} C_{i}\right): r V_{1}\left(1+K_{1} C_{1}{ }^{\prime}\right): r V_{2}\left(1+K_{1} C_{1}{ }^{\prime}+K_{2} C_{2}{ }^{\prime}\right): \ldots:$ $r V_{i}\left(1+K_{1} C_{1}{ }^{\prime}+K_{2} C_{2}{ }^{\prime}+\ldots+K_{i} C_{i}{ }^{\prime}\right)$

$$
=a_{1}: a_{2}: \ldots: a_{i}: a_{1}{ }^{\prime}: a_{2}{ }^{\prime}: \ldots: a_{i}{ }^{\prime} \text {. }
$$

The coefficients $K_{i}$ are intended to account for both the increased field strength and the changed mobility below the protein boundary.

The conditions necessary for these simple proportionality relations to hold can be derived from the equation for the conductivity change across a boundary given by equation (23) of Svensson (1946):

$$
\frac{\kappa_{2}}{\kappa_{1}}=\frac{u_{2}}{u_{1}}\left[1-\frac{C}{\sum \frac{c_{i 1} u_{i 1}}{u_{i 1}-\mathrm{U}}}\right] .
$$

This implies

$$
-\frac{\Delta \kappa}{\kappa_{1}}+\frac{\Delta u}{u_{1}}=\frac{u_{2}}{u_{1}} \frac{C}{\sum \frac{c_{i 1} u_{i 1}}{u_{i 1}-\mathbf{U}}} .
$$

However,

$$
-\frac{\Delta \kappa}{\kappa_{1}}+\frac{\Delta u}{u_{1}}=\frac{\left(V_{a i}-V_{i}\right) \kappa_{2}}{V_{i} \kappa_{1}}
$$

for a protein $i$, where

$$
V_{a i}=\frac{u_{i 2} I}{\kappa_{2}} \text { and } V_{i}=\frac{u_{i 1} I}{\kappa_{1}},
$$

$u_{i 2} / u_{i 1}$ of the protein ions being taken equal to $u_{2} / u_{1}$. After elimination of $\kappa_{2} / \kappa_{1}$,

$$
\frac{V_{a i}-V_{i}}{V_{i}}=\frac{C}{\sum \frac{c_{i 1} u_{i 1}}{u_{i 1}-\mathrm{U}}-C} .
$$

The conditions for equation (1) to hold are then (a) that $C$ be small compared with $\Sigma \frac{c_{i 1} u_{i 1}}{u_{i 1}-\mathbf{U}}, K_{i}=\frac{1}{V_{i}} \frac{V_{a i}-V_{i}}{C_{i}}$ being then an approximation to $\left(\frac{1}{V_{i}} \frac{d V_{a i}}{d C_{i}}\right)_{c_{i} \rightarrow 0}$ at constant buffer salt concentration in the supernatant fluid, and $(b)$ that $u_{i 2} / u_{i 1}$ for the protein ions be approximately equal to $u_{2} / u_{1}$ for the buffer ions. It is considered that these conditions are satisfied in the experiments described in the present paper on account of the small specific charge of the protein ions, and since the changes in $\mathrm{pH}$ across the protein boundaries could be assumed to be negligible. If other protein components are present on both sides of the protein boundary, the $V_{i}$ refer to the velocity in buffer in the absence of the other protein ions as stated in the definition. The use in equation (1) of the apparent concentrations, where strictly the true concentrations are concerned, was taken as an approximation for cases in which the concentrations of the protein components on both sides of protein boundaries could be assumed to differ little. When two components have very similar mobilities, the true concentrations must be used in the calculation, as is done in a later section of this paper. Equation (1) has been derived for a special purpose for which an extended treatment was not considered necessary, the advantages conferred by simplicity outweighing the limitations due to the imposed conditions.

\section{EXPERIMENTAL}

The electrophoresis experiments were carried out in the Tiselius apparatus fitted with the Philpot-Svensson diagonal edge optical system. In place of the diagonal edge a wire of $0.19 \mathrm{~mm}$. diameter was used. The technique of electrophoresis has been described by several authors (see Svensson, 1946; Longsworth, 1946; Wiedemann, 1946). As can be seen from the base lines in the accompanying photographs, the optical system used has not the perfection of spherical correction attainable by more recent developments. It was tested for inadequacies not obvious in the appearances of the base lines by measuring the areas given by salt boundaries which had been moved to four different positions on each limb, and it was found that the range of variation in the values for the areas $( \pm 1.5 \%)$ did not appreciably exceed the experimental error. The optical system was also tested by comparing the patterns given by a lens (one lens of focal length $200 \mathrm{~cm}$. and another of focal length $25 \mathrm{~cm}$.) placed at different positions in a vertical plane at the place of the $U$-tube. A mm. scale, placed between the limbs of the $\mathbf{U}$-tube, gave a practically undistorted image (without the cylindrical lens; within $\pm 0.05 \mathrm{~mm}$. in all and within $\pm 0.03_{5} \mathrm{~mm}$. in 31 out of 34 pairs of measurements).

Serum was diluted with phosphate buffer of $\mathrm{pH} 8.0$ and ionic strength $\mu=0 \cdot 1$, and dialyzed against 2 l. of buffer in the refrigerator at $0-4^{\circ}$ for several days with frequent mixing. The $U$-tube was of the medium-size type requiring about $10.5 \mathrm{ml}$. to fill the bottom compartments and the bridge. Currents between 3 and $20 \mathrm{~mA}$. were used (crosssection of the $\mathbf{U}$-tube $=75$ sq.mm.). The bath temperature was $0 \cdot 1^{\circ}$. The base lines were photographed before each experiment was started, after the bottom compartment had been set in alignment. The areas were measured with a planimeter on enlarged tracings. The method of dividing the areas was that of Svedberg \& Pedersen (1940) as used by Longsworth (1946). For grossly asymmetric curves, like those of the $\beta$ and $\gamma$ peaks, curves of different steepness were used for the extrapolation of each side. The small component behind the $\beta$-globulin was always included in the $\gamma$-globulin. The displacements of the albumin and the $\alpha$-globulin boundaries only were measured, since the position of the $\beta$-globulin boundary on the descending side is disturbed by the presence of the $\beta$-anomaly, and the relative migration velocity of the $\gamma$ peak is too small for the accuracy of measurement required. The area of the $\beta$ globulins, however, can be obtained correctly from records taken 10-120 min. after the current has been stopped, when the anomalous part of the curve has shrunk to within the measurable range. Any material flowing off or collecting in the $\beta$ boundary should, according to Moore \& Lynn (quoted by Abramson et al. 1942, p. 186), not alter the value for the area underneath the $\beta$-globulin peak. The difference in the displacements of the $A$ and $\alpha$ boundaries was determined from measurements of the centroidal ordinates of the gradient curves (Longsworth, 1943; Dole, 1945) to an accuracy of $0.3 \mathrm{~mm}$. or better. Ordinates at intervals of $0.2 \mathrm{~mm}$. were placed parallel to the streaks on the pattern (originating from dust particles in focus on the plate), and 
the position of the centroidal ordinate was obtained by $\mathbf{x}=\sum_{i} x_{i} y_{i} / \sum_{i} y_{i}$, where $x_{i}$ is the distance in the direction of migration and $y_{i}$ that along the ordinate. While it was possible to locate the $A$ boundaries in the descending limb to within $\pm 0 \cdot 1 \mathrm{~mm}$. or better, the location of the $\alpha$ boundary was often made more uncertain since an appreciable part of the curve was obtained by extrapolation. The centroidal ordinates for the ascending albumin boundaries at concentrations higher than $1 \mathrm{~g} . / 100 \mathrm{ml}$. were obtained by extrapolating the top part of the gradient curve which fell outside the range covered by the photographic record. The area of this part of the peak was calculated by difference of the total area of the ascending $A$ peak and that of the available part, the total area of the ascending $A$ peak from that of the descending $A$ peak by multiplication by $\rho$, and $\rho$ was obtained as defined above assuming the total areas under all peaks (including $\delta$ and $\epsilon$ ) to be equal on both sides. All these values are crude approximations, but errors in neither of them affect the position of the centroidal ordinate significantly. If the missing part of the curve is taken to be symmetrical with respect to an ordinate half way between the highest (equal) ordinates measured, then the same value for the centroidal ordinate is obtained, independent of the shape of this part of the curve, which may be between that of an equilateral triangle and a rectangle. The most probable shape of the missing part of an asymmetrical curve will be between that of a rectangle and that of a triangle, the sides of which are in the same ratio as the areas under the curve outside the highest ordinates measured, but nearer that of the latter. The differences in the positions of the centroidal ordinates for the extreme cases were in the present experiments between 0.016 and $0.033 \mathrm{~mm}$. The position of the centroidal ordinate used in the calculation for Exps. 3 and 7-10 of Table 1 was that calculated for the missing part of the curve as an asymmetrical triangle.

The displacements were measured from the position of the original boundary, and no correction was applied for volume changes due to the electrode reactions (Longsworth, 1943; Dole, 1945).

\section{RESULTS}

\section{The relative migration velocities of the $\alpha_{2}$ and $A$ boundaries}

For a system of four components such as that of the four groups of proteins in human serum (phosphate buffer) the appropriate equations are:

$$
\begin{aligned}
& V_{1}\left(1+K_{4} C_{4}+K_{3} C_{3}+K_{2} C_{2}+K_{1} C_{1}\right): \\
& V_{2}\left(1+K_{4} C_{4}+K_{3} C_{3}+K_{2} C_{2}\right): r V_{1}\left(1+K_{1} C_{1}{ }^{\prime}\right): \\
& r V_{2}\left(1+K_{1} C_{1}{ }^{\prime}+K_{2} C_{2}{ }^{\prime}\right)=a_{1}: a_{2}: a_{1}{ }^{\prime}: a_{2}{ }^{\prime} .
\end{aligned}
$$

They can be solved for $r$ and the $K_{i}$ if all concentrations and displacements are known and if a relationship is assumed between the coefficients $K_{i}$. For the present purpose the values of $K_{1}$ and $r$ were calculated from (5) by assuming $K_{4}$, $K_{3}$ and $K_{2}$ to be equal to $K_{1}$. The mean values from both patterns of the apparent relative concentrations (assuming, as is usual, equal refractive indices for all components), multiplied by the protein concentration of the starting solution, were taken as the values for the apparent concentrations on the descending side. The concentrations of albumin and $\alpha_{2}$-globulin on the ascending side were calculated from the mean values by multiplication by $\rho$ as the best approximation to the values of the apparent concentrations. Where the area of the albumin peak on the ascending side could not be measured, the areas on the descending pattern only were used for calculation. The area of $\epsilon$, which could in no serum pattern be defined with any certainty, was taken as one fifth of $\delta$. The ratio $\epsilon / \delta$ for the equilibrated solution of albumin in Fig. $1 \mathrm{~A}$ and $\mathrm{B}$ was found to be $0 \cdot 27$. On account of the nature of equation (5) there was no necessity for any great accuracy in the location of the position of the original boundary, provided all measurements on both sides were taken from points equidistant from the centre line between the partition plates. In order to make use of patterns where no record of the position of the original boundary, had been taken, values for $K_{1}$ and $r$ were bracketed within the limits obtained by the use of the distances of the boundaries from the $\delta$ and the descending $\gamma$ boundaries respectively.

Table 1 shows the results obtained from ten electrophoresis experiments on normal and pathological sera. The values for $r$ incorporate the ratio of the cross-sections of both sides of the $\mathbf{U}$-tube, for which no correction has been applied. They are, furthermore, much dependent on the assumed relationship between the $K_{i}$ and they do not, therefore, represent an experimental approach to obtaining the ratio of velocities as stated in their definition, but merely an aid for obtaining values for $K_{i}$, in the calculation of which they are made to cancel out.

The coefficient $K_{1}$ was about $0 \cdot 1$ in all experiments, signifying an increase of about $10 \%$ in the migration velocity for an increase of $1 \mathrm{~g} . / 100 \mathrm{ml}$. in the protein concentration. Such a high value was rather unexpected, and therefore the effects on $K_{1}$ of the uncertainty involved in the values employed for $\rho$ and $\delta$ were tested by repeating the calculation, putting in their place $\frac{1}{2}(\rho+1)$ or $\frac{1}{2} \delta$. (The altered value of $\rho$ was used with the same relative concentrations of the components, while that of $\delta$ involved a change in the relative concentrations, mainly in that of $\gamma$-globulin.) For example, using the value $\frac{1}{2}(\rho+1), K_{1}$ in Exp. 3 was then found to be lowered by $0 \cdot 001$. Using $\frac{1}{2} \delta$ in Exp. 2 the same value for $K_{1}$ was found. By taking $K_{4}=K_{3}=K_{2}=0$ the value for $K_{1}$ in Exp. 10 was increased by 0.0009. By taking $K_{4}=K_{3}=K_{2}=2 K_{1}$ the value for $K_{1}$ was 0.0026 lower ; that for $K_{2}$, etc., worked out to $0 \cdot 19$, which is improbably high. Thus a drastic change in the assumptions about the coefficients or errors in the estimates of $\rho$ or $\delta$ did not alter $K_{1}$ to any considerable extent.

Another estimate of $K_{1}$, not involving proteins other than albumin, was therefore obtained by comparing the distances migrated by the ascending albumin boundaries at different concentrations of serum. Serum was diluted to a total protein content of $0.61,1.17$ and $2.38 \mathrm{~g} . / 100 \mathrm{ml}$, and all three samples dialyzed together against 21 . of buffer. The three electrophoresis experiments on them (Exps. 1, 2 and 3 of Table 1) were carried out on one day against the same supernatant fluid and without change of the liquids in the electrode vessels. 
Table 1. Coefficient $K_{1}$ derived from the relative migration velocities of the $\alpha_{2}$ and $A$ boundaries

\begin{tabular}{|c|c|c|c|c|c|}
\hline $\begin{array}{l}\text { Exp. } \\
\text { no; }\end{array}$ & Diagnosis & $\begin{array}{c}\text { Conc. of } \\
\text { protein } \\
\text { (g./ } \\
100 \mathrm{ml} .)\end{array}$ & $\begin{array}{c}\text { Albumin } \\
\left(+\alpha_{1}\right) \\
\text { (\% of } \\
\text { total) }\end{array}$ & $K_{1}$ & $r$ \\
\hline $\left.\begin{array}{l}1 \\
2 \\
3\end{array}\right\}$ & Normal & $\left.\begin{array}{l}0 \cdot 6 \\
1 \cdot 2 \\
2 \cdot 4\end{array}\right\}$ & 65 & $\begin{array}{l}0.21 \\
0 \cdot 12 \\
0 \cdot 12\end{array}$ & $\begin{array}{l}1 \cdot 12 \\
1 \cdot 17 \\
1 \cdot 32\end{array}$ \\
\hline & . & & & $\begin{array}{c}\text { ( } \delta \text { as } \\
\text { origin) }\end{array} \begin{array}{l}\left(\gamma_{\text {desc }} \text { as }\right. \\
\text { origin })\end{array}$ & $\begin{array}{c}\text { ( } \delta \text { as }\left(\gamma_{\text {deec. }} \text { as }\right. \\
\text { origin) origin) }\end{array}$ \\
\hline $\begin{array}{c}4 \\
5 \\
6 \\
7 \\
8 \\
9 \\
10\end{array}$ & $\begin{array}{l}\text { Normal } \\
\text { Normal } \\
\text { Plasma-cell myeloma } \\
\text { Breast carcinoma } \\
\text { Breast carcinoma } \\
\text { Cirrhosis of liver }\end{array}$ & $\begin{array}{l}1 \cdot 4 \\
1.5 \\
1 \cdot 9 \\
2 \cdot 4 \\
\left\{\begin{array}{l}2 \cdot 5 \\
2 \cdot 5 \\
2 \cdot 5\end{array}\right.\end{array}$ & $\begin{array}{l}62 \\
63 \\
50 \\
70 \\
58 \\
60 \\
57\end{array}$ & $\begin{array}{l}0.08-0.12 \\
0.11-0.15 \\
0.13-0.17 \\
0.07-0.11 \\
0.09-0.12 \\
0.10-0.14 \\
0.09-0.13\end{array}$ & $\begin{array}{l}1 \cdot 13-1 \cdot 18 \\
1 \cdot 20-1 \cdot 27 \\
1 \cdot 29-1 \cdot 36 \\
1 \cdot 23-1 \cdot 29 \\
1 \cdot 28-1 \cdot 35 \\
1 \cdot 33-1 \cdot 42 \\
1 \cdot 30-1 \cdot 36\end{array}$ \\
\hline
\end{tabular}

Table 2. Migration velocities of albumin boundaries and apparent composition of serum (in $\mathrm{g} .100 \mathrm{ml}$.) at different concentrations

(Phosphate buffer pH 8.0, $\mu=0 \cdot 1,120 \mathrm{~min}$. at $12 \cdot 0 \mathrm{~mA}$.)

\begin{tabular}{|c|c|c|c|c|c|c|c|c|c|c|c|c|c|}
\hline \multicolumn{2}{|c|}{ Concentration of total protein $(\mathrm{g} . / 100 \mathrm{ml}$.) } & \multicolumn{3}{|c|}{$0 \cdot 61$} & \multicolumn{3}{|c|}{$1 \cdot 17$} & \multicolumn{3}{|c|}{$2 \cdot 38$} & \multicolumn{3}{|c|}{$1 \cdot 4^{*}$} \\
\hline Distances migrated (mm.) & $\begin{array}{l}\text { Ascending side } \\
\text { Descending side }\end{array}$ & & $\begin{array}{r}28 \cdot{ }^{2} \\
{ }_{4}\end{array}$ & & & $\begin{array}{r}29 \cdot{ }_{3} \\
26 \cdot{ }_{2}\end{array}$ & & & $\overbrace{}^{30 \cdot{ }_{0}}$ & & & 二 & \\
\hline & & Asc. & Desc. & Mean & Asc. & Desc. & Mean & Ásc. & Desc. & Mean & Ásc. & Desc. & Mean \\
\hline \multicolumn{2}{|c|}{ Albumin $\alpha_{2}\left(+\alpha_{1}\right)$} & $\begin{array}{l}4.47 \\
0.50 \\
0.92 \\
1.01\end{array}$ & $\begin{array}{l}4 \cdot 35 \\
0 \cdot 57 \\
0 \cdot 88 \\
1 \cdot 10\end{array}$ & $\begin{array}{l}4.41 \\
0.53 \\
0.90 \\
1.06\end{array}$ & $\begin{array}{l}4 \cdot 65 \\
0 \cdot 33 \\
0 \cdot 84 \\
1 \cdot 08\end{array}$ & $\begin{array}{l}4 \cdot 37 \\
0 \cdot 50 \\
0 \cdot 89 \\
1 \cdot 14\end{array}$ & $\begin{array}{l}4.51 \\
0.41 \\
0.87 \\
1.11\end{array}$ & - & $\begin{array}{l}4.56 \\
0.44 \\
0.90 \\
1.00\end{array}$ & - & $\begin{array}{l}4.52 \\
0 \cdot 60 \\
0 \cdot 83 \\
0 \cdot 95\end{array}$ & $\begin{array}{l}4.47 \\
0.43 \\
0.95 \\
0.99\end{array}$ & $\begin{array}{l}4 \cdot 50 \\
0 \cdot 54 \\
0 \cdot 89 \\
0 \cdot 97\end{array}$ \\
\hline \multicolumn{2}{|c|}{ Albumin $\left(+\alpha_{1}\right)+\alpha_{2}$} & $4 \cdot 97$ & $4 \cdot 92$ & $4 \cdot 94$ & 4.98 & $4 \cdot 87$ & 4.92 & - & $5 \cdot 00$ & 一 & $5 \cdot 12$ & 4.96 & $5 \cdot 04$ \\
\hline \multicolumn{2}{|l|}{$\frac{\delta(\text { or } \epsilon)}{\text { Total area } \delta}$} & - & - & - & 0.08 & - & - & $0 \cdot 16$ & - & - & $0 \cdot 11$ & 0.055 & 一 \\
\hline
\end{tabular}

* Veronal buffer pH 8.6 as used by Longsworth, Curtis \& Pembroke (1945).

Table 2 shows the distances migrated in equal times at equal currents. They were measured from the position of the original boundary.

The increase on the ascending side in the distance migrated by the albumin boundary is $6 \%$ for an increase in the albumin concentration (corrected for dilution in the ascending limb) of about $1 \mathrm{~g} . / 100 \mathrm{ml}$. The coefficient $K_{1}$ therefore works out to be $0 \cdot 06$. The results of the area measurements are included to show the effect of the concentration on the apparent relative concentrations of the components. The sum of $A\left(+\alpha_{1}\right)+\alpha_{2}$ should be used for comparison on account of the uncertainty involved when extrapolating the curve between $A\left(+\alpha_{1}\right)$ and $\alpha_{2}$. The change in the apparent concentration of $A\left(+\alpha_{1}\right)+\alpha_{2}$ for the whole practicable range is about $2 \%$ in the descending patterns, but this is here within the experimental error. Perlmann \& Kaufman (1945) found a change in the proportion of the albumin to total protein, as calculated from the areas given by human plasma in veronal buffer, from $58 \cdot 4$ to $54 \cdot 6 \%$ as the total protein concentration was changed from 2.5 to $0.94 \mathrm{~g} . / 100 \mathrm{ml}$. (4 to $1.5 \mathrm{mg}$. $\mathrm{N} / \mathrm{ml}$.). The change in this case is about $6.5 \%$.
Simultaneous measurements of velocities at different concentrations. Small differences in migration velocities could be measured more satisfactorily in simultaneous experiments than otherwise; one such experiment is reported here in detail, since the technique leads to a new method of comparing mobilities. The method was based $(a)$ on the theoretical consideration that the $\delta$ boundary should be completely absent when the starting solution is a solution of a single component obtained from between the ascending boundary and the $\delta$ boundary and when the buffer used as supernatant is the same as that into which the protein component has migrated previously (Lagercrantz, 1945), and $(b)$ on the assumption that for low concentrations of the protein the changes in buffer-ion concentrations across the ascending boundary are proportional to the protein concentration.

Experimental evidence for $(a)$ was obtained during a preparation of serum albumin. An albumin solution ( $18 \mathrm{ml}$.) free from $\alpha_{1}$ and $\alpha_{2}$ was prepared by several electrophoretic runs on undiluted serum dialyzed against veronal buffer (pH 8.6). The pooled samples were then electrophoresed into veronal 
buffer and they proved to be free from $\alpha_{2}$ or $\alpha_{1}$. This solution was then dialyzed with frequent stirring against four changes of 2 1. each of phosphate buffer of pH 8.0 during 12 days. Electrophoresis into phosphate buffer gave the patterns as shown in Fig. $1 \mathrm{~A}$ and B. Apart from the albumin boundary and a

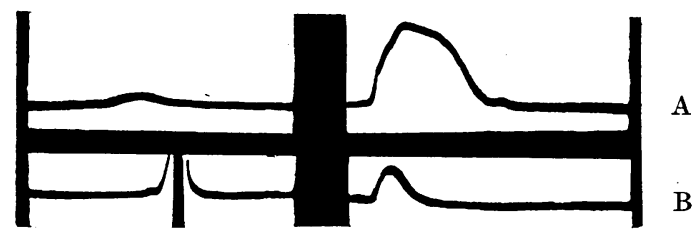

Fig. 1. Electrophoretic patterns of serum albumin free from $\alpha_{1}$ and $\alpha_{2}$-globulin. A, ascending albumin and $\delta$, after $57 \mathrm{~min}$. at $20 \mathrm{~mA}$., tilt $60^{\circ}$ to the horizontal; $\mathrm{B}$, descending albumin and $\epsilon$, after $92 \mathrm{~min}$. at $20 \mathrm{~mA}$, tilt $60^{\circ}$; phosphate buffer $\mathrm{pH} 8 \cdot 0, \mu=0 \cdot 1$. The direction of migration is to the left for ascending and to the right for descending patterns.

minute component ahead of it, only the $\delta$ and $\epsilon$ peaks are seen. The area of the $\delta$ peak amounted to $16 \%$ of the total area (protein concentration $1.8 \mathrm{~g} . /$ $100 \mathrm{ml}$.). This electrophoresis was continued for $6.5 \mathrm{hr}$. at $20 \mathrm{~mA}$., while the ascending boundary was kept in position by steady compensation, and there was no disturbance by convection on the ascending side, whereas on the descending side convection began when the $\delta$ boundary had reached the bridge. The albumin solution from the ascending side, which was expected to show no $\delta$ effect, was separated. The remainder of the solution was mixed with the solution, dialyzed against phosphate in the ratio $3: 2$ and electrophoresed (with an interruption of $11 \mathrm{hr}$.) for $12 \mathrm{hr}$. at $20 \mathrm{~mA}$. The $\delta$ effect was now smaller than in the previous run, since a greater part of the starting solution had had the buffer salt concentration reduced during the previous experiment. This run also lasted much beyond the time at which the $\delta$ boundary passed the bridge; and thus the concentration in buffer salts on the descending side must have been further reduced, approaching that on the ascending side. The final run was made with a solution consisting of 2 parts of albumin solution from the ascending side, 1 part of the remainder from the bridge and descending side, and a small amount of buffer to make up the volume required. A small $\delta$ peak was observed, the area of which indicated a change in refractive index of $1.7 \%$ of that at the descending $A$ boundary.

If the assumption that the change in migration velocity at a protein boundary is proportional to the change in protein concentration holds in the range of concentrations used, then no gravitational instability should arise, and no additional $\delta$ boundary should appear in the experiment carried out as follows: The layer formed by the electrophoresis of serum between the first two boundaries on the ascending side, $A$ and $\alpha_{2}$, was recovered from the $\mathbf{U}$-tube, and diluted with buffer to reduce the concentration as much as possible consistent with retaining a distinct boundary peak. This dilute protein solution was then used as supernatant in place of the buffer in the top compartment on the ascending side in the next electrophoresis of the same serum. In both runs portions of the same dialyzed serum and the same buffer against which it has been dialyzed were used. The interference of $\alpha_{1}$ can be disregarded, since its concentration in the solution of the diluted albumin is negligible and the difference in mobilities between $A$ and $\alpha_{1}$ in phosphate buffer is small.

The difference between the migration velocity of a boundary of a concentrated and that of a diluted albumin solution can be measured directly by the change in the distance between these two boundaries. Table 3 gives the experimental details, and Fig. 2 shows the patterns of an experiment carried out with normal serum. Assuming that the $\delta$ boundary has moved $2.5 \mathrm{~mm}$. backward with reference to the position of the original boundary as was observed to be the case in Exp. 3 (Table 1), the distance migrated by the $A_{\text {conc. }}$ boundary in $145 \mathrm{~min}$. was $33 \mathrm{~mm}$. The change in the distance $A_{\text {conc. }}-A_{\text {dil. }}$ was $2.1 \mathrm{~mm}$. and the distance migrated by the $A_{\text {dil. }}$ boundary $30.9 \mathrm{~mm}$. The velocity of the large albumin boundary does not represent the migration velocity of the albumin ions since these ions are present on both sides of the boundary (Svensson, 1946). The difference between the velocity of the boundary, and the true velocity of the albumin ions behind the boundary, can be estimated in the present case in a simple manner on account of the assumption that a change in the concentrations of any ion species cannot occur either behind the $A_{\text {dil. }}^{\prime}$ or between the

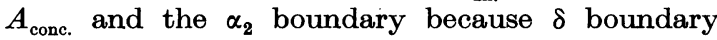
effects, apart from those normally present, are bound to be absent in these regions. Owing to the difference in velocity of the $A_{\text {conc. }}$ and $A_{\text {dill }}$ boundaries the volume/unit cross section occupied by the dilute albumin solution has been reduced by $r V_{1}\left(K_{1} C_{\text {conc. }}^{\prime}-K_{1} C_{\text {dil. }}^{\prime}\right)$. The amount of albumin in the volume $r V_{1}\left(K_{1} C_{\text {conc. }}^{\prime}-K_{1} C_{\text {dil. }}^{\prime}\right)$ is $r V_{1} K_{1}\left(C_{\text {conc. }}^{\prime}-\right.$ $C_{\text {dil. }}^{\prime}$ ) $C_{\text {dil. }}^{\prime}$. This amount appears in the layer of concentrated albumin, the volume of which (per unit cross section) is increased by

$$
\frac{r V_{1} K_{1}\left(C_{\text {conc. }}^{\prime}-C_{\text {dil. }}^{\prime}\right) C_{\text {dil. }}^{\prime}}{C_{\text {conc. }}^{\prime}-C_{\text {dil. }}^{\prime}}
$$

The length (= volume/unit cross section) of the layer of concentrated albumin is therefore greater by this amount than it would have been if the concentrated 
Table 3. Relative migration velocities of concentrated and diluted serum albumin

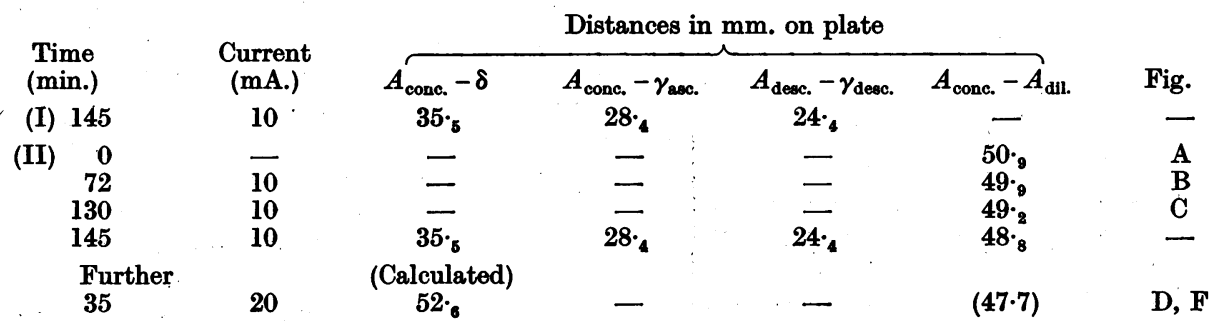

Normal serum, total protein 6:7 g./100 ml., dialyzed undiluted against 2 l. phosphate buffer $(\mathrm{pH} 8 \cdot 0, \mu=0 \cdot 1)$ for $22 \mathrm{hr}$.,

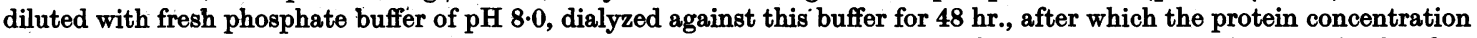
was $2.02 \mathrm{~g}$. $/ 100 \mathrm{ml}$. (Kjeldahl); electrophoresis (I) for $145 \mathrm{~min}$. at $10 \mathrm{~mA}$., then for $126 \mathrm{~min}$. at $20 \mathrm{~mA}$; $0.3 \mathrm{ml}$. of $\alpha_{2}$-free albumin from ascending side added to $4 \mathrm{ml}$. buffer and this solution used as supernatant on the ascending side in the experiment following (II), with the starting solution of diluted serum and buffer the same as in (I); the contents of the electrode vessels were not changed; $10 \mathrm{~mA}$. corresponds to about $5 \cdot 3 \mathrm{~V}$. $/ \mathrm{cm}$.; the optical enlarging factor along the direction of the current was 1.12. The composition of the starting solution as calculated from the descending pattern was: $A\left(+\alpha_{1}\right)=1.34, \alpha_{2}=0.11, \beta=0.30, \gamma=0.27 \mathrm{~g} . / 100 \mathrm{ml}$.; the concentration between the $A$ and $\alpha_{2}$ boundaries on the ascending side $\left(C_{\text {cono. }}^{\prime}\right)$ was approximately $1.34 \times \rho$, i.e. 1.2 ; the concentration between the $A_{\text {cono. }}$ and the $A_{\text {dil. }}$ boundaries $\left(C_{\text {dil. }}^{\prime}\right)$ was $0.07 \mathrm{~g} . / 100 \mathrm{ml}$. (calculated from the areas).

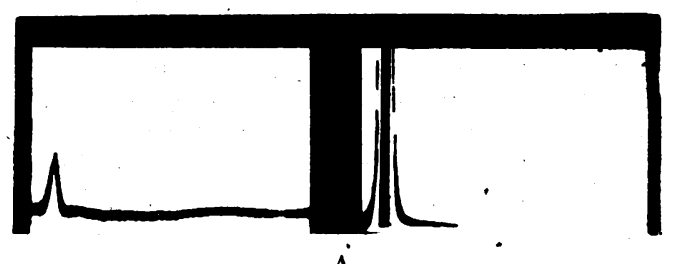

$\dot{A}$

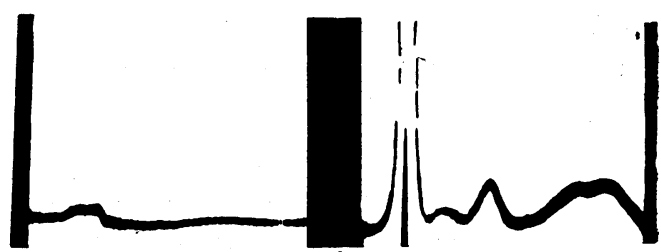

C

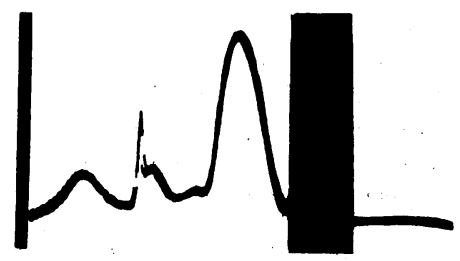

$\mathbf{E}$

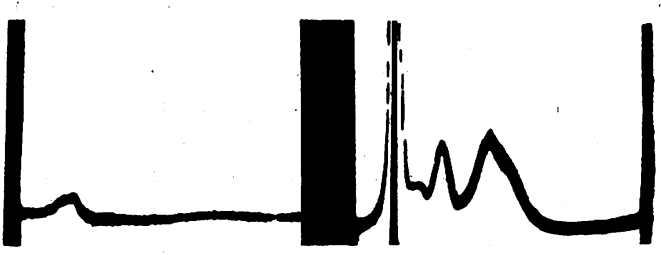

B

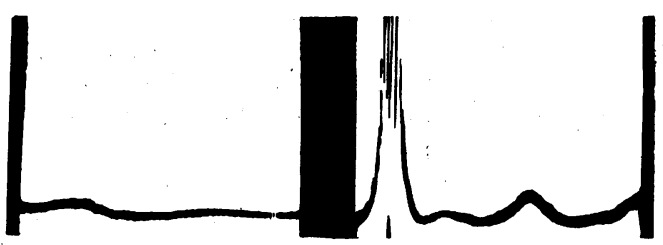

D

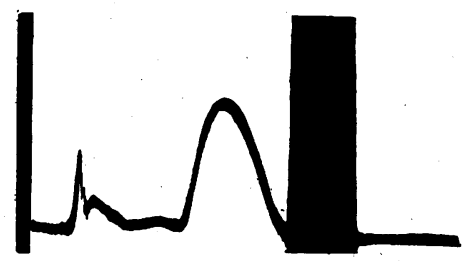

$\mathbf{F}$

Fig. 2. Migration velocities of the boundaries of dilute and concentrated albumin: A-D, ascending patterns, tilt $45^{\circ}$; $A, B$ and $C$ after 0,72 and $130 \mathrm{~min}$. at $10 \mathrm{~mA}$., $D$ after 145 min. at $10 \mathrm{~mA}$. and further $35 \mathrm{~min}$. at $20 \mathrm{~mA}$; E, F, descending patterns, tilt $45^{\circ} ; \mathrm{E}$, after $145 \mathrm{~min}$. at $10 \mathrm{~mA}$; F, after further $35 \mathrm{~min}$. at $20 \mathrm{~mA}$. Phosphate buffer pH 8.0, $\mu=0 \cdot 1$. 
albumin had migrated into buffer alone. Per unit distance migrated by the $A_{\text {dill }}$ boundary, this is $\frac{r V_{1} K_{1} C_{\text {dil. }}^{\prime}}{r V_{1}\left(1+K_{1} C_{\text {dil. }}^{\prime}\right)}$, or very nearly $K_{1} C_{\text {dil. }}^{\prime}$. In the present case this is $0.4 \%$ of $30.9 \mathrm{~mm}$., or $0.13 \mathrm{~mm}$. This figure has to be subtracted from $2 \cdot 1$ (the change in the distance between the two $A$ boundaries), and the relative increment in velocity/unit concentration, $K_{1}$, becomes $\frac{1.97}{30 \cdot 9(1 \cdot 2-0 \cdot 07)}$, i.e. 0.056 .

The salt concentration in the layer of diluted albumin will be smaller than that which would be obtained after electrophoresis of albumin at this concentration into buffer, by the extent to which $K_{1}$ increases as the protein concentration increases. Hence a gravitationally unstable region might be expected to appear behind the $A_{\text {dil. }}$ boundary. This region would sink as soon as it was formed and would appear as an additional peak at the $A_{\text {conc. }}$ boundary. Such disturbances are vanishingly small if the concentration of the dilute albumin solution is below $0.1 \mathrm{~g} . / 100 \mathrm{ml}$.

It should be noted that separation into two components is seen at the boundary of the dilute but not at that of the concentrated solution. This is in accordance with the theory as will be seen in a later section of the paper. Fig. $2 \mathrm{D}$ and $\mathrm{F}$ show the patterns after the $\delta$ and $\gamma$ boundaries have reached the bridge. The appearance of the descending pattern has barely changed, since the convections were restricted to the region below the albumin boundary.

The high value for $K_{1}$, obtained when calculated from the relative positions of the $\alpha_{2}$ and $A$ boundaries in serum patterns, suggests a disturbance in the region of the $\alpha_{2}$ boundary, due to inverted density gradients or a mobility ratio for the $\alpha_{2}$-globulin across the descending albumin boundary, which deviates considerably from that assumed constant for all ions in Svensson's equation. The velocity of the $\alpha_{2}$ boundary relative to that of the $A$ boundary appears too large on the ascending or too small on the descending side or both. The discrepancy in the distance $A-\alpha_{2}$ is about $0.5 \mathrm{~mm}$. on either the ascending or descending side in a normal pattern of serum diluted to a total protein concentration of $1.5 \mathrm{~g}$. $/ 100 \mathrm{ml}$. (phosphate buffer $\mathrm{pH} 8.0$ and $\mu=0.1$ ), in which the distance between $A$ and $\delta$ is $35 \mathrm{~mm}$. The data given by Lagercrantż (1945) for the corrected mobilities of the components of normal human serum at $\mathrm{pH} 7.7$ and $\mu=0.05$ support the present findings of the anomalous position of the $\alpha_{2}$ boundary. The values for $\alpha$-globulin are 5.57 and $5.06 \times 10^{-5} \mathrm{~cm}^{2} \mathrm{~V} .{ }^{-1}$ sec. $^{-1}$ for the ascending and descending sides respectively. At $\mu=0 \cdot 2$, Lagercrantz found agreement between the values for the mobilities of $\alpha$-globulin.
The net charge of serum albumin. The experimental determination of $K_{1}$ makes it possible to calculate the average specific charge of serum albumin at $\mathrm{pH} \mathrm{8.0.} \mathrm{If} C$, the equivalent concentration of the colloid ion in Svensson's equation (23) (quoted above), is replaced by $Q_{8} C_{1} \times 10^{-2}\left(Q_{s}\right.$ being the specific charge, expressed as valence/g.) then from equation (4)

$$
K_{1}=\frac{Q_{s} \times 10^{-2}}{\sum \frac{c_{i 1} u_{i 1}}{u_{i 1}-\mathrm{U}}-C},
$$

and $Q_{s}$ can be calculated, $C$ being neglected (or used as a correction term after $Q_{s}$ has been found). The following numerical values were used:

$$
\begin{aligned}
& c_{\mathrm{Na}}+{ }_{1}=-c_{\mathrm{HPO}_{4}}{ }_{1}=0.067 \times 10^{-3} \text { equivalents } / \mathrm{ml} .{ }^{*} \\
& u_{\mathrm{Na}}+_{1}=2 \cdot 35, \dagger \quad u_{\mathrm{HPO}_{4}}=-2 \cdot 19 \text {, }
\end{aligned}
$$

$U=-0.7$ (mobilities in $\left.10^{-4} \mathrm{~cm}^{2} \mathrm{~V} .^{-1} \mathrm{sec}^{-1}\right), \S$ $K_{1}=0.06$. $Q_{s}$ then becomes $-2.8 \times 10^{-4}$. The net charge of human serum albumin (molecular weight 70,000 ) at $0^{\circ}, \mathrm{pH} 8 \cdot 0$, and $\mu=0 \cdot 1$ is therefore about - 19. Cohn, Oncley, Strong, Hughes \& Armstrong (1944) quote - 18 as the net charge of human serum albumin at $\mathrm{pH} \mathbf{7 \cdot 4}$. If the values for horse serum albumin B, calculated by Abramson et al. (1942) from a combination of electrophoresis, diffusion, and sedimentation data at $25^{\circ}$ and $\mu=0 \cdot 1$, are extrapolated to a $\mathrm{pH}$ of 8.0 , values of about -20 are obtained. The extrapolated values for $\mathrm{pH} \mathrm{8.0}$ of the valence, calculated from titration data by the same authors, are about -30 and -21 for $\mu=0.1$ and 0 respectively.

An accuracy of $10 \%$ in the value for the net charge as determined here implies an accuracy of $1 \%$ in the values for the boundary displacements. Both the corrections for the volume changes in the electrode vessels and those caused by changes in the solvent concentration at the boundary, which were discussed by Dole (1945), seem in this case of minor importance. One advantage of this method is its independence of the starting conditions in cases in

* A small error only is introduced by disregarding the presence of $\mathrm{H}_{2} \mathrm{PO}_{4}^{-}$(about $10 \mathrm{~mol} . / 100$ ) and assuming all phosphate to be in the form of $\mathrm{HPO}_{4}{ }^{2}$.

$\dagger$ Landolt-Börnstein, Physikalisch-Chemische Tabellen.

$\ddagger$ Landolt-Börnstein, extrapolated to $0^{\circ}$ and $0.033 \mathrm{~mol}$. $/ 1$. from a value given for $25^{\circ}$ at infinite dilution, assuming the same relative dependency on temperature and concentration as the $\mathrm{SO}_{4}=$ ion.

$\S$ Extrapolated from values for different ionic strengths and $\mathrm{pH}$ given by Lagercrantz (1945), who derived the values for the mobilities from conductivity measurements on particular sections of the contents of the $U$-tube, and others (Stenhagen, 1938; Longsworth \& MacInnes, 1940b; Blix, 1941; Kendall, 1941; Chargaff, Ziff \& Moore, 1941; Cohn et al. 1944; Moore, 1945). 
which the Donnan equilibrium has not been completely established, since the protein concentration below the boundary can be estimated by chemical methods or from the eleatrophoretic pattern. But the main merit appears to be that the net charge of a leading ion can be obtained without previous separation from other components.

\section{Boundary relationships with two components of similar mobilities}

The statement of the conservation of matter applied to the protein ions overtaking an ascending boundary leads, with the assumptions made earlier in this paper, to an expression for the concentration ahead of the boundary. For the two fastest components the relationship is

$$
\begin{aligned}
& \left(V_{1}-V_{2}\right)\left(1+K_{2} \mathrm{G}_{2}^{\prime}+K_{1} \mathrm{G}_{1}^{\prime}\right) \mathbf{G}_{1}^{\prime} \\
& \quad=\left[V_{1}\left(1+K_{1} C_{1}^{\prime}\right)-V_{2}\left(1+K_{2} \mathrm{G}_{2}^{\prime}+K_{1} \mathrm{G}_{1}^{\prime}\right)\right] C_{1}^{\prime}, .
\end{aligned}
$$

where $\mathbf{C}_{1}^{\prime}, \mathbf{G}_{2}^{\prime}$ are the true concentrations behind the boundary of the slower component.

$$
\text { With } 1+K_{2} \mathbf{C}_{2}^{\prime}+K_{1} \mathbf{C}_{1}^{\prime}=e \text {, }
$$

$$
\begin{array}{r}
C_{1}^{\prime}=\frac{1}{2 K_{1}}\left[+\left|\sqrt{ }\left\{\left(1-\frac{V_{2}}{V_{1}} e\right)^{2}+4 K_{1} e \mathbf{C}_{1}^{\prime}\left(1-\frac{V^{2}}{V_{1}}\right)\right\}\right|\right. \\
\left.-\left(1-\frac{V_{2}}{V_{1}} e\right)\right] .
\end{array}
$$

With $\mathbf{G}_{2}^{\prime} / \mathbf{G}_{1}^{\prime}=n, K_{2} / K_{1}=p$, and $V_{1} / V_{2}=e$ (i.e. the percentage difference in the mobilities being the sameras the percentage increment in the velocity due to the protein concentration behind the boundary), $\quad C_{1}^{\prime}=\mathbf{C}_{1}^{\prime} \sqrt{ }(p n+1)$.

The separation $S$ of the boundaries is given by

$$
S=\frac{\mathrm{C}_{1}^{\prime}}{C_{1}^{\prime}}\left(V_{1}-V_{2}\right)\left(1+K_{1} \mathrm{G}_{1}^{\prime}+K_{2} \mathrm{G}_{2}^{\prime}\right)
$$

A limiting case of interest arises when $p=1$ and $V_{1}$ nearly equal to $V_{2}$; the faster component will adjust itself ahead of the boundary to a concentration nearly equal to the total concentration behind the boundary, independent of the relative concentrations in the mixture. When the mobilities are similar and in addition $p>1$, a gravitationally unstable region may be formed ahead of the boundary of the slower component.

It can be seen by inspection of equation (5) that, by accumulation, the faster component can increase in concentration ahead of a boundary to a multiple of that behind the boundary. It can thus reverse the ratio of the apparent concentrations of two components under conditions normally adhered to, such as, for example, a concentration of proteins of $1 \mathrm{~g} . / 100 \mathrm{ml}$. if the mobilities of the components differ by as much as $5 \%$. The following example illustrates this. Fig. 3 shows the $A_{1}, A_{2}$ (Blix, Tiselius \& Svensson, 1941 ; Hoch \& Morris, 1945) and $\alpha_{2}$ boundaries after an electrophoresis at $\mathrm{pH} 8 \cdot 0$, and the $\alpha A, \beta A$ (Luetscher, 1939), and a small component (possibly $\alpha_{1}$ ) after an experiment at $\mathrm{pH} 4 \cdot 0$. The apparent concentration of $A_{1}$, the fastest com-

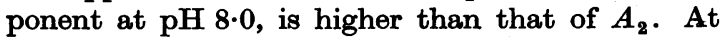
$\mathrm{pH} 4 \cdot 0$, where the serum components migrate in the

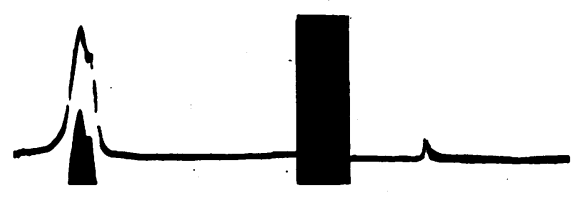

A
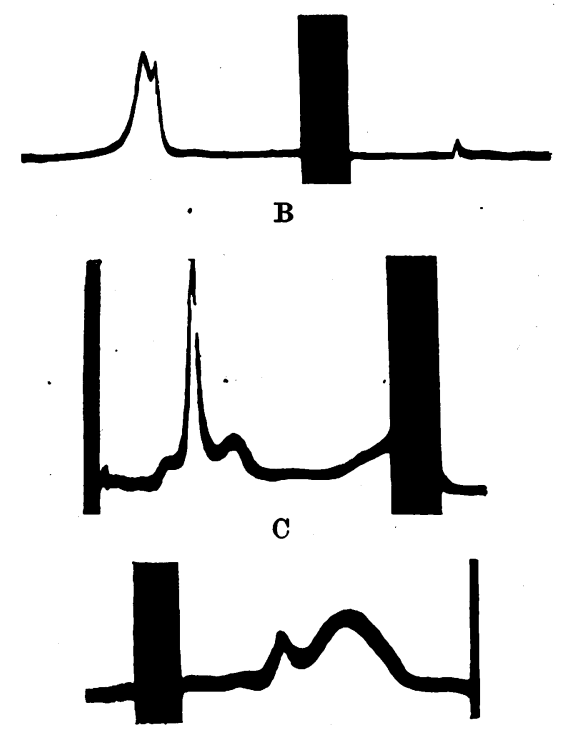

D

Fig. 3. Apparent proportions of the components of serum albumin. A, B, ascending patterns, showing albumin and $\alpha_{2}$ boundaries after prolonged electrophoretic runs on serum. Protein concentration $2 \cdot 4 \mathrm{~g}$. $/ 100 \mathrm{ml}$.; phosphate buffer $\mathrm{pH} \mathrm{8.0, \mu}=0 \cdot 1$. Comparison of $\mathrm{B}$ with $\mathrm{A}$ shows the reproducibility after the serum had been kept for 16 days at $\mathrm{pH} 8$ in the refrigerator. $A$, after $550 \mathrm{~min}$. at about $19.5 \mathrm{~mA}$., tilt $67^{\circ}$ to the horizontal; $B$, after 540 min. at 19-19.5 mA., tilt $70^{\circ}$. $\mathrm{C}$ ascending and D descending patterns of serum albumin free from $\alpha_{2}$, obtained from experiment of Fig. $3 \mathrm{~B}$; tilt $25^{\circ}$ to the horizontal; protein concentration $0 \cdot 29 \mathrm{~g}$. $/ 100 \mathrm{ml}$.; acetate buffer $\mathrm{pH} 4, \mu=0.02$.

reverse order and where the serum albumin shows two components ( $\alpha A$ and $\beta A$ ) having a much greater difference in mobility than that of the two components at $\mathrm{pH} 8 \cdot 0$, it is also the faster component $(\alpha A)$ which appears higher in concentration. As a consequence of equation (5) these observations suggest that the two components at $\mathrm{pH} 8.0$ were the same as those at $\mathrm{pH} 4.0$ and not that they were 
different, as might appear from their relative areas, although they may be so for other reasons.

The degree of separation for a particular case of a 2 : 3 mixture of two proteins was calculated for two total concentrations of 1.2 and $0.1 \mathrm{~g} . / 100 \mathrm{ml}$. protein. The velocities at infinite dilution were taken to differ by $7 \%\left(V_{1} / V_{2}=1 \cdot 07\right)$. The degree of separation for the higher concentration (with $K_{1}=K_{2}=0.06$, $p=1$, and $\mathrm{C}_{\mathrm{i}}^{\prime}=0.48$ ) works out to $1 / 1.58$ times the separation at infinite dilution. For the lower concentration $\left(\mathbf{C}_{1}^{\prime}=0.04\right)$, the degree of separation is very nearly equal to (1/1.04 times) the separation at infinite dilution. If the latter were about $2 \mathrm{~mm}$. one would expect a separation of $1.9 \mathrm{~mm}$. at $0.1 \mathrm{~g} . /$ $100 \mathrm{ml}$. protein and a separation of $1.27 \mathrm{~mm}$. at $1.2 \mathrm{~g} . / 100 \mathrm{ml}$. protein.
The relationship between concentrations of a protein component ahead and behind a descending protein boundary is given by

$$
\begin{array}{r}
C_{2}=\frac{1}{2 K_{2}}\left[-\left|\sqrt{ }\left\{\left(\frac{V_{1}}{V_{2}} g-1\right)^{2}-4 K_{2} g \mathbf{C}_{2}\left(\frac{V_{1}}{V_{2}}-1\right)\right\}\right|\right. \\
\left.+\left(\frac{V_{1}}{V_{2}} g-1\right)\right],
\end{array}
$$

where $g=1+K_{1} \mathbf{G}_{1}+K_{2} \mathbf{C}_{2} ; \mathbf{C}_{1}, \mathbf{C}_{2}$ are the true concentrations of the components ahead of the boundary of the faster component.

The extent to which analyses of serum patterns may give values for concentrations that are different from those of the original mixture can be assessed

Table 4. Apparent proportions of the faster component of a two-component mixture, calculated from equations (5) and (7)

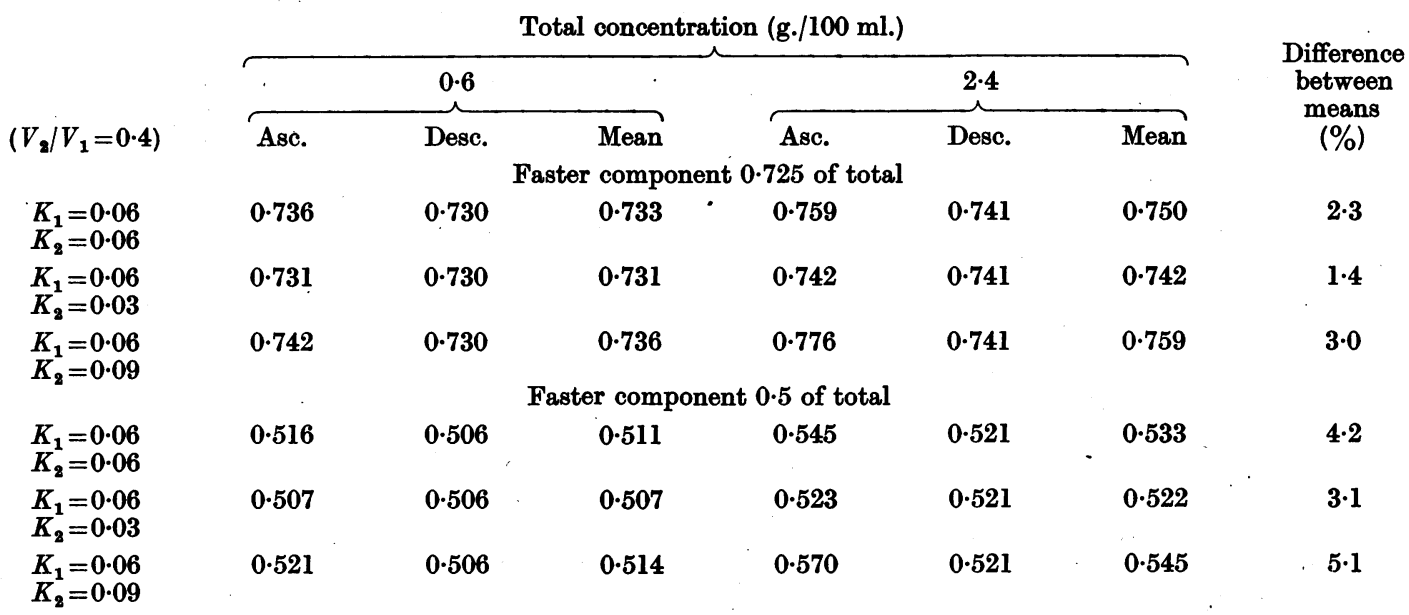

The differences between the values for the total concentrations of 0.6 and $2.4 \mathrm{~g} . / 100 \mathrm{ml}$. are here slightly underestimated since the dependency of $K_{i}$ on the protein concentration has not been taken into account. The numerical evaluation of equation (4a) suggests that a value for $K_{1}$ of 0.06 should be increased by about $7 \%$ when the protein concentration rises by $1 \mathrm{~g}$. $/ 100 \mathrm{ml}$.

An example for such conditions might be represented by Fig. 2C. The separation of the two components at the small-albumin boundary is between 2 and $3 \mathrm{~mm}$. At the large-albumin boundary no split could be observed, but a difference in the width of the boundary of about $0.7 \mathrm{~mm}$. was found between patterns $B$ and $C$ (measured at 10-15 mm. above the base line). This corresponds to a spreading of about $1.4 \mathrm{~mm}$. during the experiment between patterns $\mathrm{A}$ and $\mathrm{C}$.

In view of the fact that other components with mobilities similar to that of the albumin, apart from $A_{1}$ and $A_{2}$, may possibly be present in small quantities, the spreading of the large albumin boundary seems in fair agreement with the theory. from Table 4, which has been comptated from equations (5) and (7) for a two-component system simulating one containing an albumin and a globulin component, of mobilities in the ratio $1: 0 \cdot 4$. The calculation was carried out for different values of $K_{2}$ and for two relative proportions of the two components, one being similar to that given in Table 2 for $\left(A+\alpha_{1}+\alpha_{2}\right):(\beta+\gamma)$, i.e. the faster component $72.5 \%$ of the total. The concentrations on the ascending side were calculated from those assumed for the original mixture by multiplication by $\rho$. Although $\rho$ is dependent on $K_{2}, K_{1}$ being kept constant, a change in $p$ of 5 or $10 \%$ affects the values given in Table 4 only slightly, and therefore $\rho$ was kept the same for all values of $K_{2}$. The values used, 
0.97 and 0.87 for the lower and higher concentrations respectively, were average experimental values found for serum.

\section{SUMMARY}

1. The anomalies in electrophoretic patterns of protein mixtures are considered theoretically for specified conditions, and the equations derived are applied to the study of normal and pathological sera.

2. The value for a coefficient which relates the change in migration velocity of protein ions to the change in protein concentration was determined experimentally for human serum albumin. It was found to be $K_{1}=0 \cdot 06$, signifying an increase of $6 \%$ in the migration velocity of an ascending boundary/ g. protein $/ 100 \mathrm{ml}$.

3. The average net charge of the albumin was calculated by inserting this value into an expression derived from the equation for the conductivity change across a colloid boundary given by Svensson (1946). A value for the valence of about -19 was found, which is consistent with that of -18 , quoted by Cohn et al. (1944) for $\mathrm{pH} 7 \cdot 4$, obtained from measurements of electromotive force.

4. The $\alpha$-globulin boundary in patterns of serum in phosphate buffer at $\mathrm{pH} 8: 0$ and $\mu=0 \cdot 1$ was found to have a slightly anomalous position relative to that of the albumin boundary.
5. A method for comparing mobilities by simultaneous measurements is outlined.

6. The calculation of the concentration relationships in a boundary region of two components reveals that the relative concentrations as deduced from the apparent concentration changes at the boundaries give a grossly erroneous picture of the concentrations in the original solution, when the value for the relative difference in the mobilities is in the region of that of $K_{1}$ or lower.

7. The degree of separation of two boundaries depends on the total concentration. The examination for electrophoretic homogeneity should be carried out at low concentrations where the separation of the boundaries is greatest and over a range of concentrations as far as the interference of diffusion allows. An experiment on human serum is described in which separation of the albumin boundary into two components was observed at a concentration of $0.07 \%$ after a migration of $31 \mathrm{~mm}$., while no separation but only broadening was seen at a concentration of $1.2 \%$.

The author wishes to thank Prof. P. Gross, Drs E. R. Holiday and C. J. O. R. Morris, and Mr W. Weinstein for constructive criticism and help with the manuscript.

While this paper was being prepared for press, a publication by Longsworth (1947) appeared dealing with related problems.

\section{REFERENCES}

Abramson, H. A., Moyer, L. S. \& Gorin, M. H. (1942). Electrophoresis of Proteins and the Chemistry of Cell Surfaces. New York: Reinhold Publishing Corporation.

Blix, G. (1941). J. biol. Chem. 137, 495.

Blix, G., Tiselius, A. \& Svensson, H. (1941). J. biol. Chem. $137,485$.

Chargaff, E., Ziff, M. \& Moore, D. H. (1941). J. biol. Chem. 139, 383.

Cohn, J. E., Oncley, J. L., Strong, L. E., Hughes, W. L. Jr. \& Armstrong, S. H. Jr. (1944). J. clin. Invest. 23, 417.

Dole, V. P. (1945). J. Amer. chem. Soc. 67, 1119.

Hoch, H. \& Morris, C. J. O. R. (1945). Nature, Lond., 156, 234.

Kendall, F. E. (1941). J. biol. Chem. 138, 97.

Lagercrantz, C. (1945). Ark. Kemi Min. Geol. 19, no. 7.

Longsworth, L. G. (1942). Chem. Rev. 30, 323.

Longsworth, L. G. (1943). J.A Amer. chem. Soc. 65, 1755.

Longsworth, L. G. (1946). Industr. Engng Chem. (Anal. ed.), 18, 219.
Longsworth, L. G. (1947). J. Phys. Coll. Chem. 51, 171.

Longsworth, L. G., Curtis, R. M. \& Pembroke, R. H. Jr. (1945). J. clin. Invest. 24, 46.

Longsworth, L. G. \& MacInnes, D. A. (1940a). J. Amer. chem. Soc. 62, 705.

Longsworth, L. G. \& MacInnes, D. A. (1940b). J. exp. Med. $71,77$.

Luetscher, J. A. (1939). J. Amer. chem. Soc. 61, 2888.

Moore, D. H. (1945). J. biol. Chem. 161, 21.

Perlmann, G. E. \& Kaufman, D. (1945). J. Amer. chem. Soc. 67, 638.

Stenhagen, E. (1938). Biochem. J. 32, 714.

Svedberg, T. \& Pedersen, K. O. (1940). The Ultracentrifuge. London: Oxford University Press.

Svensson, H. (1943). Ark. Kemi Min. Geol. 17, no. 14.

Svensson, H. (1946). Ark. Kemi Min. Geol. 22, no. 10.

Tiselius, A. (1930). Inaugural Dissertation, Uppsala.

Wiedemann, E. (1946). Schweiz. med. Wschr. 76, 241. 